\title{
Ultrasonic Welding of Folding Boxboards
}

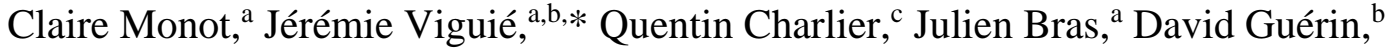 \\ Barthélémy Harthong, ${ }^{\mathrm{c}}$ Didier Imbault, ${ }^{\mathrm{c}}$ Robert Peyroux, ${ }^{\mathrm{c}}$ Martine Rueff, ${ }^{\mathrm{a}}$ \\ Laurence Leroy, ${ }^{\mathrm{b}}$ and Marie Caron ${ }^{\mathrm{b}}$
}

\begin{abstract}
Today's environmental concerns are pressuring industries to substitute paper-based materials in place of plastics in many sectors including packaging. However, assembling papers and paperboards using environmentally friendly solutions remains a technological challenge. In this context, ultrasonic (US) welding is an alternative to adhesives. In this work, the potential of US welding to assemble folding boxboards was investigated. Folding boxboards are commonly coated to enhance printability. This coating is generally composed of mineral pigments (85 to $90 \%$ ) and polymer binders (10 to $12 \%$ ). This study evaluated whether the presence of the coating layer allows the assembly of paperboards by US welding. Results indicated that welding coated folding boxboards is possible provided that coating weight and binder content are high enough. The mechanical performances of the welded boards met the requirements of most packaging applications. Adhesion in the welded joint resulted from a combination of thermoplastic (melting and flowing of the binder) and thermoset (degradation reactions) effects. However, it was not possible to assemble coated folding boxboards without degrading the welding zone. While the materials and process need to be optimized, this work represents a big step forward toward the adhesive-free assembling of paper-based materials.
\end{abstract}

Keywords: Ultrasonic welding; Papers and paperboards; Adhesive-free assembling

Contact information: a: Univ. Grenoble Alpes, CNRS, Grenoble INP, LGP2, F-38000 Grenoble, France; b: Centre Technique du Papier (CTP), F-38044 Grenoble, France; c: Univ. Grenoble Alpes, CNRS, Grenoble INP, 3SR, F-38000 Grenoble, France;

*Corresponding author: jeremie.viguie@lgp2.grenoble-inp.fr

\section{INTRODUCTION}

Papers and boards are mostly bio-sourced, recyclable, and biodegradable materials. To address environmental issues, they are interesting alternatives to plastics in many sectors. Many industrial groups and major distributors are making efforts to reduce their use of plastic packaging (Abboud 2019). In this context, the use of paperboard as lightweight stiff packaging material is growing in the food, cosmetic, and drug industries. Almost 10 million tons were produced in Europe in 2018 (CEPI 2018).

Paperboard is a thick stratified paper-based material with a basis weight between 180 and $450 \mathrm{~g} / \mathrm{m}^{2}$. Each layer may be made of a specific grade of pulp. For instance, in folding boxboards, the inner layers are composed of low density mechanical pulps (ligninrich) to provide high stiffness to the folding board structure, while chemical pulps (ligninfree) are used for the outer layers to provide strength and whiteness. Cohesion of the stratified structure is often promoted by the addition of starch-based solutions between the layers and on the paperboard surfaces (Li et al. 2019). Finally, paperboard is often coated to improve surface properties (smoothness, whiteness, and gloss), to guarantee printability, 
and/or to provide other functionalities like barrier properties (Andersson 2008). The coating weight can reach $20 \mathrm{~g} / \mathrm{m}^{2}$ for a $450 \mathrm{~g} / \mathrm{m}^{2}$ paperboard. Common coating formulations used for printability purposes are composed mainly of mineral pigments and binders. Pigments bring printability, while binders favor coating deposition, homogeneity, and cohesion. Pigments can be precipitated calcium carbonate, ground calcium carbonate, kaolin, talc, gypsum, alumina trihydrate, titanium dioxide, or silica. Binders are either water-soluble or insoluble. Natural polymers including starch, protein, cellulose derivatives, and carboxymethyl cellulose, or synthetic polymers such as polyvinyl alcohol are common water-soluble binders. Insoluble binders include latexes of styrene butadiene, styrene acrylate, or polyvinyl acrylate. Pigments represent 80 to $95 \mathrm{wt} \%$ of the coating formulation.

Folding board boxes are generally assembled using glues and adhesives formulated with oil-based polymers such as poly(vinyl acetate) (PVAc), polyethylene (PE), or ethylene vinyl acetate (EVAc). These glues are either water-based, solvent-based, or hot melt adhesives, which can cause potential contamination by mineral oils. They also worsen the recyclability of these materials by increasing the required amount of energy and by creating additional waste. Hence, an adhesive-free process efficient to assemble folding board boxes would be of great interest for environmental, economic, and health \& safety prospects.

Ultrasonic (US) welding is a possible alternative to the use of adhesive to assemble papers and paperboards. It is already widely used for bonding thermoplastic parts, assembling nonwovens, or sealing packaging. The method includes converting a highfrequency electrical signal into mechanical vibrations capable of generating localized heating at the interface between two parts in contact. Heat generation in plastic materials results from friction and viscous dissipation within the material exposed to the vibrations (Levy et al. 2014). The localized increase in temperature melts the thermoplastic polymer, which results in the welding of the two parts. The potential of ultrasonic welding for bonding $100 \%$ lignocellulosic papers has been recently investigated (Regazzi et al. 2019). For papers containing high lignins and hemicelluloses contents (50\% in total), the adhesion strength generated by welding is almost equivalent to the one obtained by gluing. Scanning electron microscopy (SEM), 3D X-ray microtomography images, and temperature measurements suggest that the development of adhesion originates to a large extent from a thermoplastic mechanism. The increase in temperature during welding triggers the flowing of lignins and hemicelluloses, which forms a matrix around the fibers at the interface. However, as suggested by the mechanics of this phenomenon, it is not possible to weld papers obtained from chemical pulp containing low hemicelluloses (15 to 20\%) and lignin (0 to $2 \%$ ) contents.

Common papers and folding boards do not present high lignin and hemicelluloses content. Indeed, lignins are generally not wanted in paper-based products mainly because of their coloration. Often, lignins and hemicelluloses are removed during the preparation of the paper pulp. However, coated paperboards may be good candidates for US welding considering the thermoplastic nature of the binders present in the coating. If the binders are able to trigger a thermoplastic-like behavior when heated, it could be possible to generate adhesion under ultrasonic compression.

This study evaluated the potential of US welding to assemble coated folding boxboards by taking advantage of the thermo-physical properties of the coating layer. A commercial folding boxboard (FBB) was coated using a specific laboratory device to study the influence of the binder content and the coated weight on the adhesion strength generated by US welding. 
Welding performances were assessed by peeling test and observation of welded specimens. The evolution of the temperature at the welded joint was measured in situ during welding. Finally, the mechanisms responsible for the development of adhesion were considered.

\section{EXPERIMENTAL}

\section{Materials}

A commercial folding boxboard (FBB) of $270 \mathrm{~g} / \mathrm{m}^{2} \pm 4 \%$ (thickness $390 \mu \mathrm{m} \pm 4$ ) was selected. It is a stratified structure composed of one inner layer made of a mixture of chemo-thermo-mechanical pulp and chemical pulp, surrounded on each side by a layer of chemical pulp. The top side of the FBB is coated twice with a pigment solution to reach around $20 \mathrm{~g} / \mathrm{m}^{2}$ coating weight for printability purpose. The coating layer is composed of 85 to $90 \%$ of mineral pigments (kaolin and precipitated calcium carbonate) and 10 to 12 $\%$ of binders (styrene acrylate). The backside of the FBB is not coated. It is surface sized with less than $0.5 \mathrm{~g} / \mathrm{m}^{2}$ of a starch-based product.

\section{Coatings}

Coatings were obtained by deposited laboratory-made formulations using a dedicated bar coating device (Elcometer Instruments, Aalen, Germany) on the uncoated side of board samples. The wire diameter of the Mayer rod was adapted to deposit different coating weights: 12,20 , and $30 \mathrm{~g} / \mathrm{m}^{2}( \pm 10 \%)$. The pigment formulation was prepared using the same pigments, binders, and additives that compose the coating of the reference FBB: kaolin and calcium carbonate as mineral pigments (70 and 30 parts, respectively), styrene acrylate (Acronal S514, BASF, Ludwigshafen, Germany) as binder, carboxymethyl cellulose (FinnFix, Nouryon, Amsterdam, The Netherlands) (0.15 parts), calcium stearate (Alfa-Aesar GmbH, Kandel, Germany) (0.5 parts), and glyoxal (Sigma Aldrich, St. Louis, MO, USA) (0.3 parts). Styrene acrylate content was adjusted between 9, 12, and 15 parts (i.e., 8.2, 10.6, and $12.9 \%$ in weight, respectively) in the various studied formulations.

The different investigated surfaces were referred to as follows: "reference" surface/coating for the top side of the FBB (coated layer of $20 \mathrm{~g} / \mathrm{m}^{2}$ with 10 to $12 \%$ of styrene acrylate binder); "uncoated" surface for the backside of the FBB; and "lab coated" surface for the samples obtained by depositing laboratory-made coating formulations on the backside of the FBB.

\section{Welding}

An ultrasonic welder (Omega III DG - MCX, Mecasonic, Juvigny, France) was used to assemble FBBs. A constant average compression stress (5 MPa) and a forced 20 $\mathrm{kHz}$ vibration of $60 \mu \mathrm{m}$ amplitude were applied simultaneously for 0.5 or $1 \mathrm{~s}$. The compression load was maintained for $10 \mathrm{~s}$ after welding. The dimensions of the board samples were $50 \times 80 \mathrm{~mm}^{2}$. The dimensions of the welded area (i.e., the surface of the horn) were $32 \times 4 \mathrm{~mm}^{2}$. The horn surface was flat and smooth. The anvil was fixed, and its surface was perfectly flat. Samples were welded at $23 \pm 2{ }^{\circ} \mathrm{C}$ and $45 \pm 5 \%$ relative humidity. 


\section{Characterizations}

\section{Temperature measurement}

The temperature at the interface between the two welded samples was measured during US welding using T-type thermocouples (copper/constantan). Thermocouples were placed between the two pieces of FBB at the center of the welding zone. An ADC-24 data logger (PicoTechnology, Cambridgeshire, UK) was used to acquire the thermoelectric voltage at a frequency of $10 \mathrm{~Hz}$. The conversion from thermoelectric voltage to temperature was obtained from the NIST ITS-90 thermocouple database. While thermocouples can concentrate the ultrasonic energy and therefore provide misleading readings (Villegas 2015), these points have been addressed previously, and a temperature monitoring procedure was established (Regazzi et al. 2019). Considering the measured temperature range and the repeatability of the results obtained with this set-up, this method provides relevant qualitative information on the heating process during the US welding of FBBs.

\section{Peeling tests}

A floating roller peeling test was performed to assess the adhesion between the welded boards using a mechanical testing machine (DY - MTS) following the recommendations of the standard ASTM D3167-10 (2017) at $152 \mathrm{~mm} / \mathrm{min}$ (6 in/min) (Fig. 1a). The floating roller fixture is made of a one-inch axle, which allows the peeling without straining and damaging the two bonded pieces. The geometry of the peeling apparatus can be an issue for materials unable to be bent at $90^{\circ}$ or $180^{\circ}$ without being damaged or plastically deformed, which is the case for a FBB of $270 \mathrm{~g} / \mathrm{m}^{2}$. Peeled samples were bonded on a metal plate using double-sided adhesive to avoid sample folding during peeling. The peeling strengths mentioned in the result section (in $\mathrm{N} / \mathrm{m}$ ) refer to the maximum load recorded during peeling over the $4 \mathrm{~mm}$ joint length. A typical curve obtained when testing welded boards is shown in Fig. 1b. Peeling strengths were averaged on at least 5 tests for each couple sample type-welding conditions.
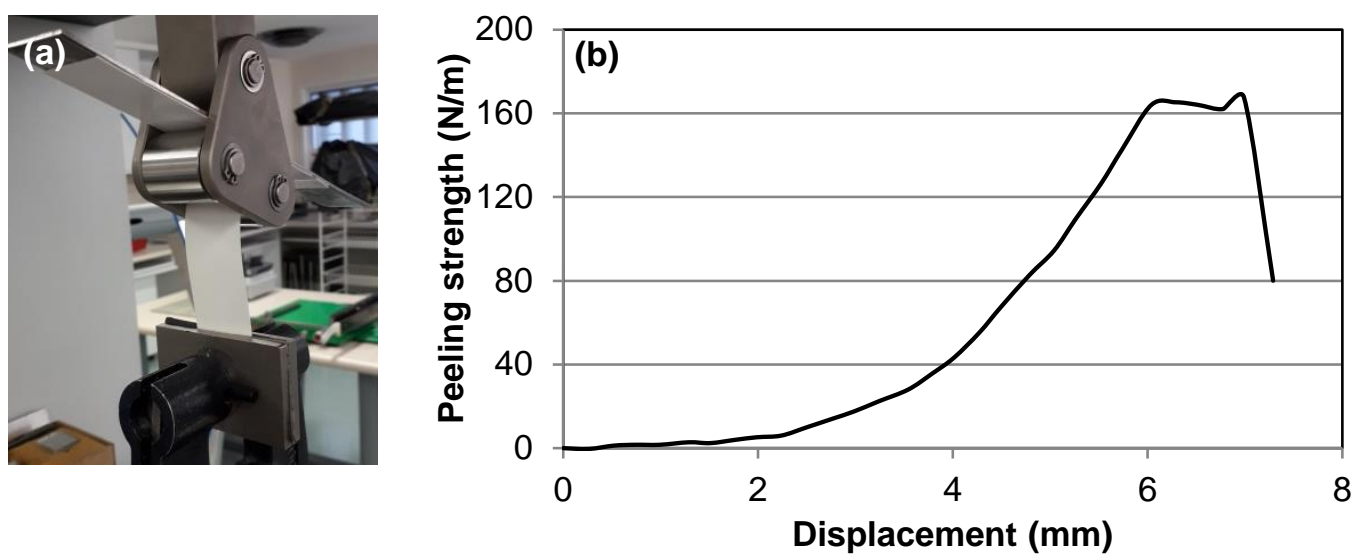

Fig. 1. (a) Floating roller apparatus used for the peeling test; (b) typical curve obtained when peeling welded boards

\section{SEM observations}

Scanning electron microscope pictures were obtained using a FEI ${ }^{\mathrm{TM}}$ Quanta 200 microscope (Hillsboro, OR, USA) in secondary (SE) and backscattered (BSE) electron mode at $15.0 \mathrm{keV}$. Samples were previously metallized using an Emitech K550X goldpalladium coating device. 


\section{RESULTS AND DISCUSSION}

\section{Welding Performance of the Reference Folding Boxboard}

The peeling strengths of the tested combinations (sample type-welding conditions) are reported in Table 1. Several combinations were tested including the asymmetrical welding reference-uncoated. The evolution of the peeling strength of all tested samples followed the same profile (Fig. 1b), but the maximum load changed according to the nature of the coating. Pictures of peeled samples are shown in Fig. 2.

Table 1. Mean Peeling Strengths of Boards Welded Using Various Welding Times and Sample Combinations.

\begin{tabular}{|c|c|c|c|}
\hline $\begin{array}{c}\text { Welding } \\
\text { Time }\end{array}$ & $\begin{array}{c}\text { Uncoated on } \\
\text { Uncoated }\end{array}$ & Reference on uncoated & Reference on reference \\
\hline $\mathbf{0 . 5} \mathbf{s}$ & $0 \mathrm{~N} / \mathrm{m}$ & $55 \pm 8 \mathrm{~N} / \mathrm{m} \mathrm{(a)}$ & $163 \pm 18 \mathrm{~N} / \mathrm{m}$ (b) \\
\hline $\mathbf{1 ~ s}$ & $0 \mathrm{~N} / \mathrm{m}$ & $106 \pm 11 \mathrm{~N} / \mathrm{m}$ (c) & $282 \pm 25 \mathrm{~N} / \mathrm{m}$ (d) \\
\hline
\end{tabular}

Note: (a), (b), (c) and (d) refer to pictures reported in Fig. 2.
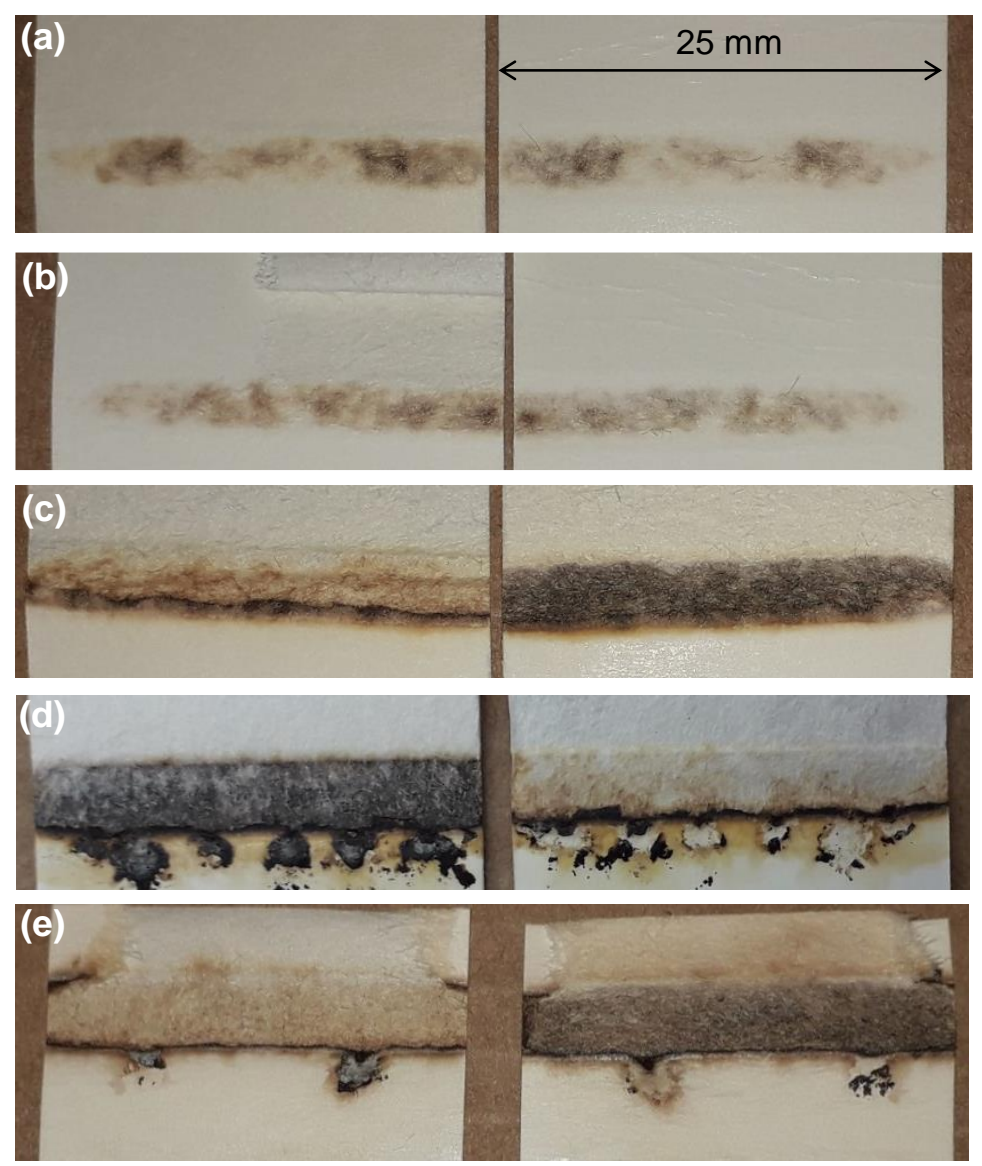

Fig. 2. Pictures of the welded board pieces after peeling for various sample combinations and welding times: (a) uncoated on reference surface, $0.5 \mathrm{~s}$, (b) reference on reference, $0.5 \mathrm{~s}$, (c) uncoated on reference, $1 \mathrm{~s}$, (d) reference on reference, 1s., (e) lab coated on lab coated, $1 \mathrm{~s}$. Related peeling strengths are reported in Table 1.

There was no adhesion when two uncoated samples were US welded. However, it was possible to weld a reference onto uncoated samples. The resulting peeling strengths 
were close to 50 and $100 \mathrm{~N} / \mathrm{m}$ for welding times of 0.5 and $1 \mathrm{~s}$, respectively. This performance is considered weak in regard the requirements for most packaging applications $(160 \mathrm{~N} / \mathrm{m})$. This configuration presents a huge applicative interest, as it is the most encountered one when assembling a folding board box. The failure profiles differed between the two welding times. For the $0.5 \mathrm{~s}$-sample, failure was mostly adhesive; it was mainly located at the interface between the two board pieces (Fig. 2a and Fig. 3a). However, some fibres were ripped from the surface, suggesting that failure propagation was also occasionally cohesive. The welded interface was slightly burnt. The failure of the 1s-sample was mostly cohesive, and the welded interface was burnt (Fig. 2c and Fig. 3b). Delamination occurred in the FBB core.

It is worth noting that the FBB was significantly densified in the welding zone as it was observed in previous studies on the ultrasonic welding $100 \%$ lignocellulosic paperlike materials (Regazzi et al. 2019) or the vibrational welding of wood (Ganne-Chédeville et al. 2006).

Two reference surfaces could be welded together, and the resulting peeling strengths were higher than the ones recorded previously $(160 \mathrm{~N} / \mathrm{m}$ and $280 \mathrm{~N} / \mathrm{m}$ for welding times of $0.5 \mathrm{~s}$ and $1 \mathrm{~s}$, respectively). This level fits well with the requirements of several flexible packaging applications but is not quite enough for most of rigid packaging applications for which a minimum level of 170 to $180 \mathrm{~N} / \mathrm{m}$ is expected. Compared with the asymmetrical reference-uncoated combination, welding together two reference surfaces clearly improved the mechanical performances. The failure of peeled samples (welding time $0.5 \mathrm{~s}$ ) was often cohesive (Fig. 2b). Some fibres were pulled out, and some delamination was observed between the outer and the inner pulp layers. The welded interface appeared slightly burnished. In contrast, the 1s-welded samples exhibited delamination that occurred more deeply in the FBB core, and the welded interface was burnt (Fig. 2d).

\section{Influence of the Binder Content and the Coating Weight}

This section reports the influence of the binder content in the coating formulation $(8.2,10.6$, and $12.9 \mathrm{wt} \%$, Fig. 3$)$ as well as the influence of the coating weight $(12,20$, and $30 \mathrm{~g} / \mathrm{m}^{2}$, Fig. 4) on the adhesion strength generated by ultrasonic welding. The investigated range of coating parameters was chosen to be representative of industrial conditions. Several combinations were tested including asymmetrical welding (lab coated on uncoated surface). All welding times were set to $1 \mathrm{~s}$.

The peeling strength increased with the binder content, regardless of the coating weight when welding lab coated on lab coated surfaces (Fig. 3a). This increase was more marked when the coating weight was lower. The peeling strength was systematically higher than 170 to $180 \mathrm{~N} / \mathrm{m}$ in the studied range of coating parameters, except for the lowest coating weight $\left(12 \mathrm{~g} / \mathrm{m}^{2}\right)$ and binder content $(8.2 \mathrm{wt} \%)$. Thus, the welded lab coated FBBs displayed good mechanical performances. Figure 2e shows the welded zone after peeling for a lab coated - lab coated welded sample with a coating weight of $12 \mathrm{~g} / \mathrm{m}^{2}$ and a binder content of $10.6 \mathrm{wt} \%$. Delamination occurred between the FBB layers rather at the welding interface, revealing a burnt interface, as observed in previous samples with the same welding conditions. The crack propagated inside the FBB after passing the welded zone, which was not observed before. The same phenomenon was observed for all higher binder contents and coating weights.

The peeling strength also increased with the binder content, regardless of the coating weight when welding lab coated on uncoated surfaces (Fig. 3b). The asymmetrical 
combination of board samples did not seem to affect the weldability, as observed with the reference board. For the lowest coating weight $\left(12 \mathrm{~g} / \mathrm{m}^{2}\right)$, the peeling strength was lower than that observed in other lab coated samples. The increase in binder content in the coating formulation resulted in a strong improvement of the peeling strength (from 0 to $100 \mathrm{~N} / \mathrm{m}$ ), which shows the importance of the binders to generate adhesion during US welding.

Note that the performance of the reference surface slightly differed from the performance of the lab coated surface at same weight and binder content (Fig. 3). Even if the coating layer composition was almost similar, the laboratory coating process is expected to form a layer that may differ from an industrial one in terms of porosity or penetration inside the fibre network.
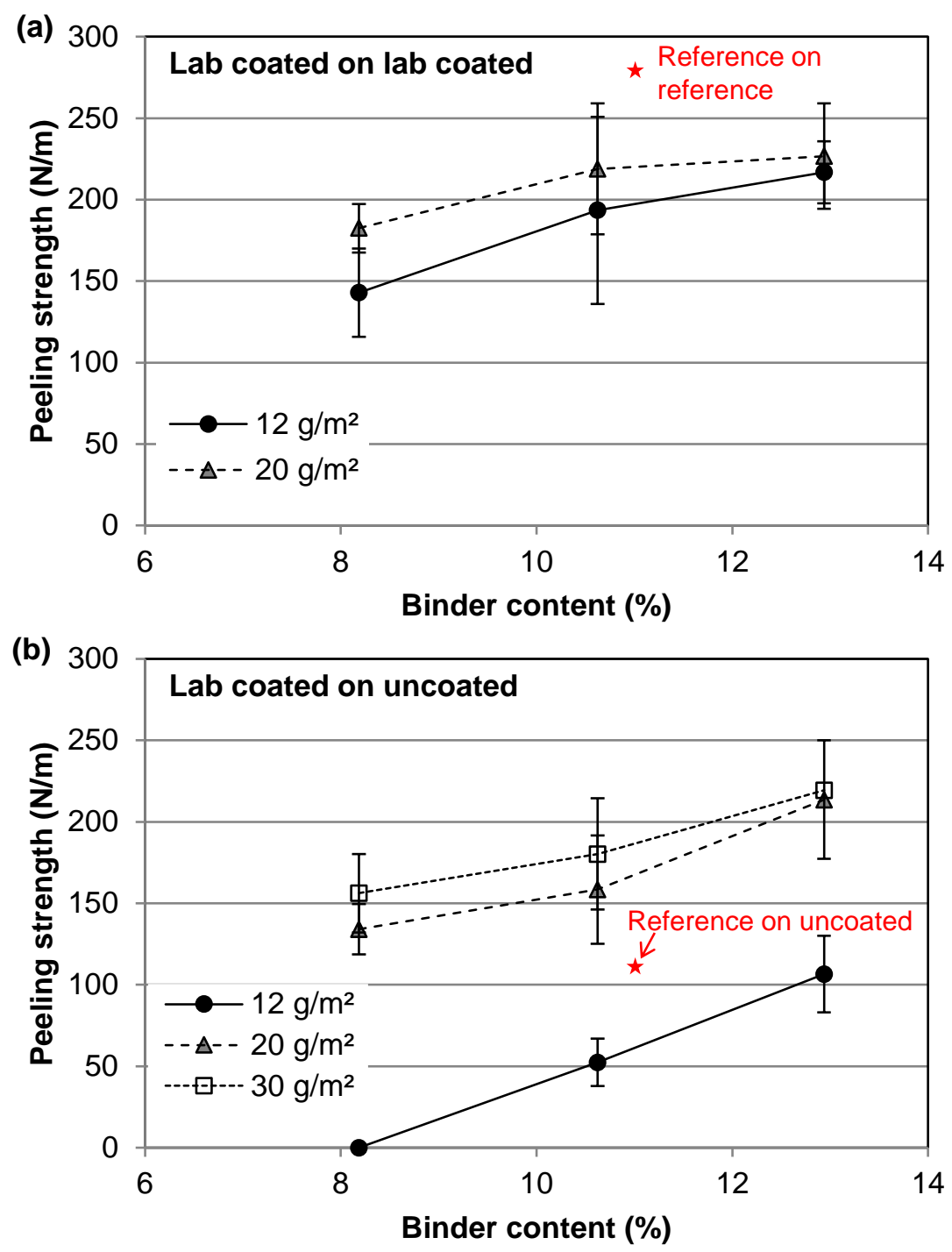

Fig. 3. Peeling strength of US welded boards versus binder content in the coating formulation for various coating weights and sample combinations: (a) lab coated on lab coated, and (b) lab coated on uncoated

The coating weight seemed also to influence the peeling strength, particularly for the lowest binder contents (Fig. 4). The total coating weight at the interface in Fig. 4 refers to the sum of the coating weights of both welded surfaces. The graph includes a 
combination of undifferentiated data obtained from symmetrical (lab coated - lab coated) and asymmetrical (lab coated - uncoated) weldings. The data did not suggest relationships between mechanical performances and the distribution of the coating between the two welded parts. Further investigations are required to validate the reliability of this representation. Nevertheless, it appeared that the peeling strength reached a plateau starting from a coating weight of 20 to $25 \mathrm{~g} / \mathrm{m}^{2}$ for all binder contents. Moreover, the peeling strength value of the plateau increased with the binder content: $220 \mathrm{~N} / \mathrm{m}$ for $12.9 \mathrm{wt} \%, 180$ to $220 \mathrm{~N} / \mathrm{m}$ for $10.6 \mathrm{wt} \%$, and 150 to $180 \mathrm{~N} / \mathrm{m}$ for $8.2 \mathrm{wt} \%$. To conclude, a minimum coating weight of 20 to $25 \mathrm{~g} / \mathrm{m}^{2}$ at the interface with a standard binder content (10 to $12 \%$ ) seems necessary to reach a satisfactory level of adhesion between two FBB pieces, meaning that the peeling strength exceeds 170 to $180 \mathrm{~N} / \mathrm{m}$. The mechanical performances can be adjusted by increasing either the coated weight or the binder content in the coating formulation. These results are in accordance with those obtained when welding referenceuncoated and reference-reference FBBs (Table 1). The total coating weight $\left(20 \mathrm{~g} / \mathrm{m}^{2}\right)$ and the binder content (10 to $12 \mathrm{wt} \%)$ were too low to guarantee significant adhesion in reference-uncoated samples, whereas the total coating weight of $40 \mathrm{~g} / \mathrm{m}^{2}$ resulted in good performance in reference-reference welded boards.

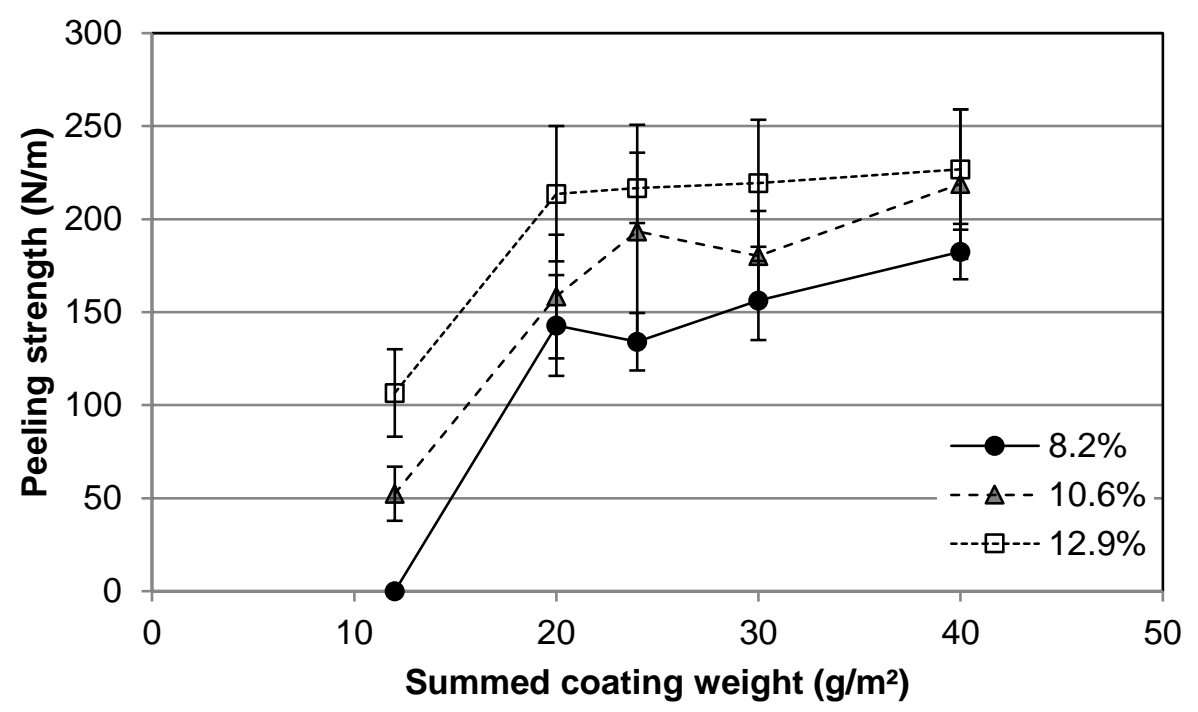

Fig. 4. Peeling strength of US welded boards versus total coating weight at the interface for various binder contents in the laboratory coating

\section{Temperature at the Welded Joint}

Figure 5 shows the evolution of the temperature during US welding for some of the sample combinations (uncoated-uncoated, reference-uncoated, and reference-reference, welding time 1s). One set of data was plotted for each combination. Temperature profiles were quite similar in the first stage: the temperature sharply increased up to 150 to $200{ }^{\circ} \mathrm{C}$. It continued increasing but with a lower and irregular slope until about $1 \mathrm{~s}$, i.e., the end of the ultrasonic vibration, which corresponded to the time when the maximum temperature was recorded. Finally, the temperature decreased exponentially back from peak to room temperature during the post-welding load. Overall, the results were consistent with temperature profiles recorded previously during the US welding of papers (Regazzi et al. 2019). During the second stage, the slope and the peak temperature differed between the tested samples. The welding of two uncoated surfaces demonstrated the highest slope and 
peak temperature $\left(370{ }^{\circ} \mathrm{C}\right)$, while the welding of two reference surfaces resulted in the lowest ones $\left(305^{\circ} \mathrm{C}\right)$. The welding of reference on uncoated surfaces showed intermediate results with a peak temperature of $340{ }^{\circ} \mathrm{C}$. As a result, the presence of the coating layer seemed to play an important role in the heat generation at the welded joint. The decrease in peak temperature appeared to be dependent on the total coating weight.

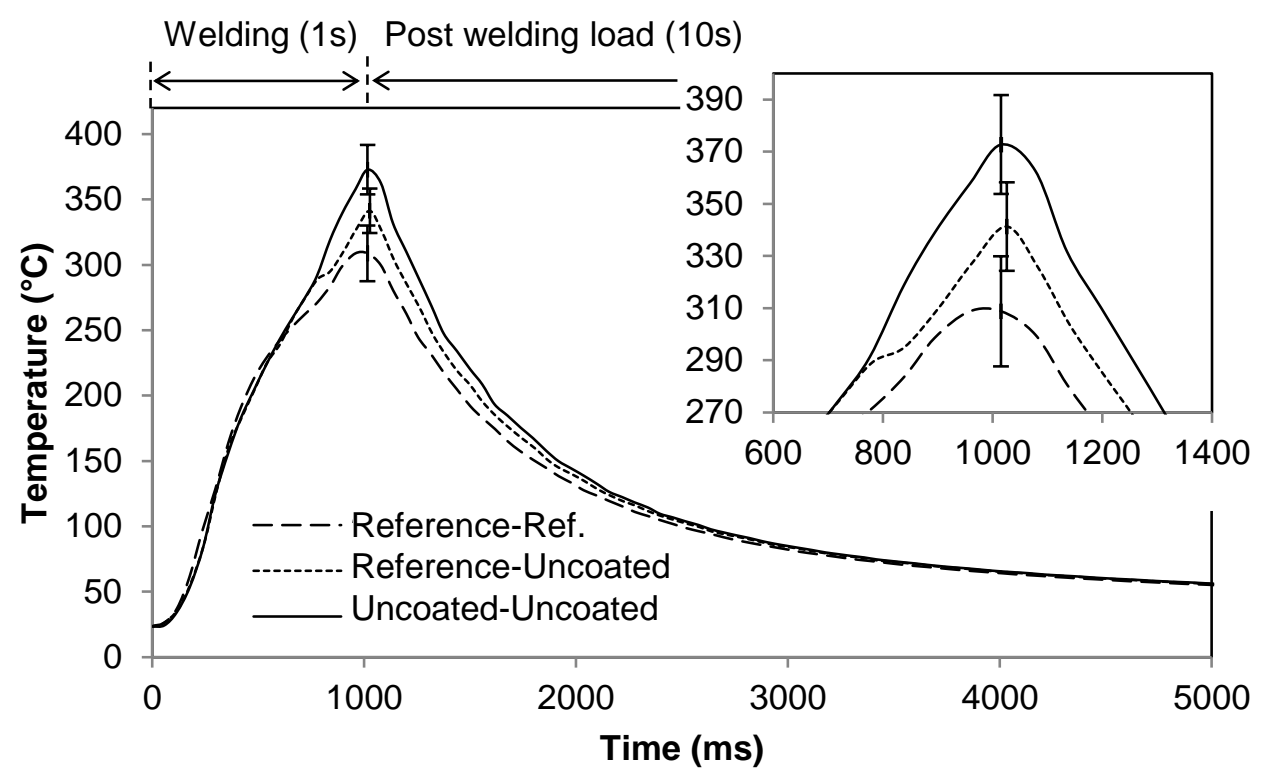

Fig. 5. Temperature at the interface during US welding of folding boxboards for three surface combinations: uncoated-uncoated, uncoated-reference, and reference-reference
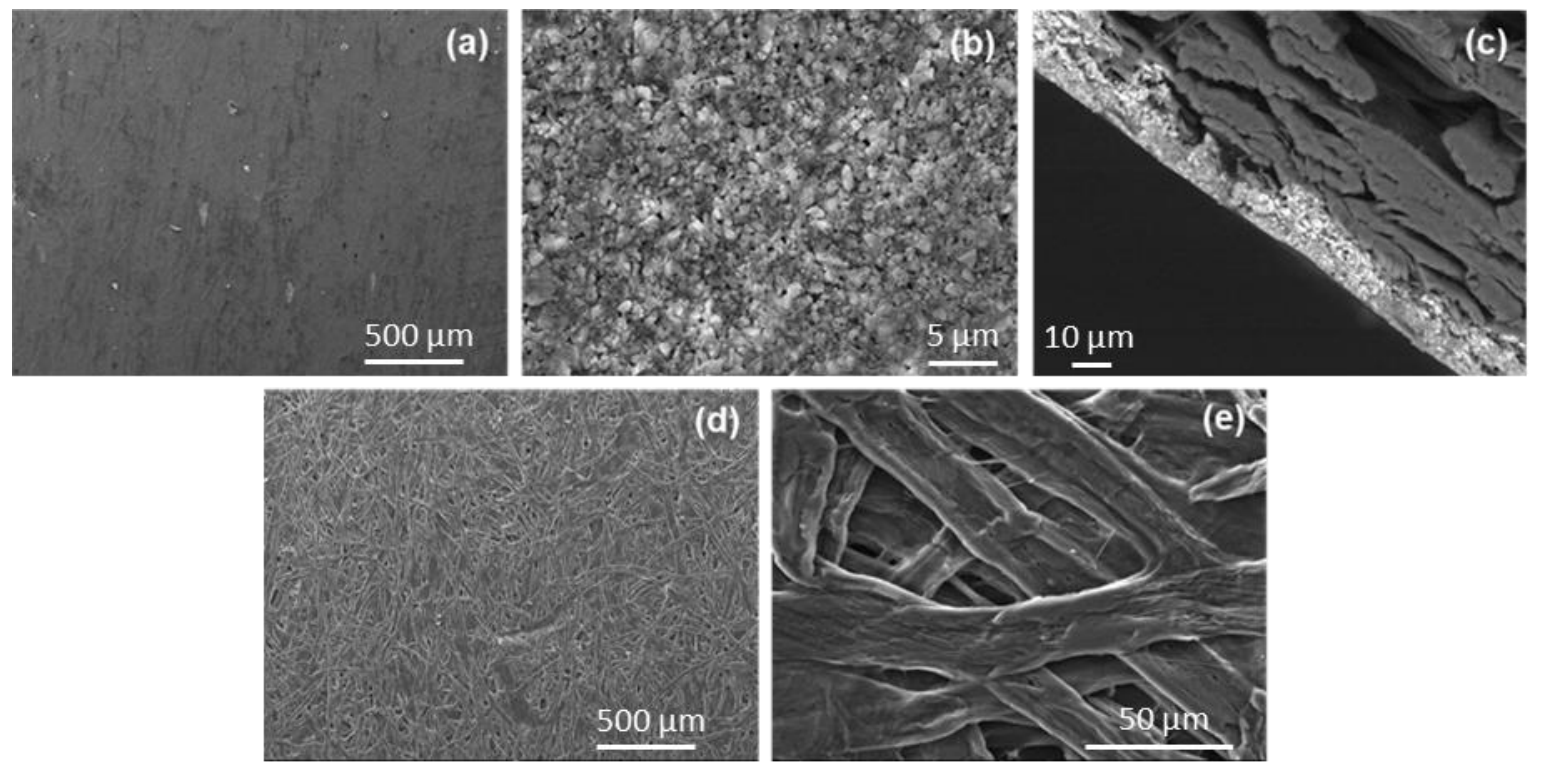

Fig. 6. SEM micrographs of the cross sections and surfaces of $(a, b, c)$ reference, $(d, e)$ uncoated samples. All micrographs were obtained in SE mode except for (c) in BSE mode

\section{Structural Characterization of the Welded Joint}

The coating layer present on reference boards was quite smooth and homogeneous (Fig. 6 a, b, c). Its thickness varied between 15 and $20 \mu \mathrm{m}$ due to the roughness of the 
fibrous layer of chemical pulp below. The size of pigment-binder aggregates ranged between 0.5 and $2 \mu \mathrm{m}$. It must be noted that the BSE mode is quite relevant to analyze the board structure due to the heavier atoms contained in mineral pigments. The contrast between coating and paper fibers allows nice observations. However, the coating itself did not reveal any strong contrast when observed by BSE. This result confirmed the good homogeneity of the blend of mineral pigments and polymer binders forming the layer.

Figures $7 \mathrm{a}$ and $\mathrm{b}$ show SEM micrographs of a reference-reference welded interface obtained with a $1 \mathrm{~s}$-welding time. The welding interface is homogeneous and continuous. It is not possible to distinguish the two initial layers. Thus, the binders were able to flow to form a continuous media at the welding interface. This mechanism seems to be responsible for the formation of the welded joint. Some cracks were observed inside the coating layer (Fig. 7b). This phenomenon is not unusual in coating layers, and it cannot be attributed specifically to welding. Some delamination was observed also inside the fibrous layer. These two observations suggest that the adhesion developed between reference boards was good enough to compete with the cohesion of the paper fiber layer. However, the multiple cracks and delamination in both fibrous and coating layers suggest that welding conditions may have been too harsh. Boards could have been damaged by the high temperature during the process. Thus, mechanical properties might have been altered, which means that the cohesion of the fiber layer may not be as strong as it was initially. It can also be noted that the boards seemed denser especially near the welding interface. This observation is consistent with previous work on the US welding of papers (Regazzi et al. 2019). Comparing Fig. 6c and Fig. 7b, the welding process resulted in a deeper penetration of the coating layer inside paper fibers. This phenomenon could also explain in part the good mechanical performances for welding joints.
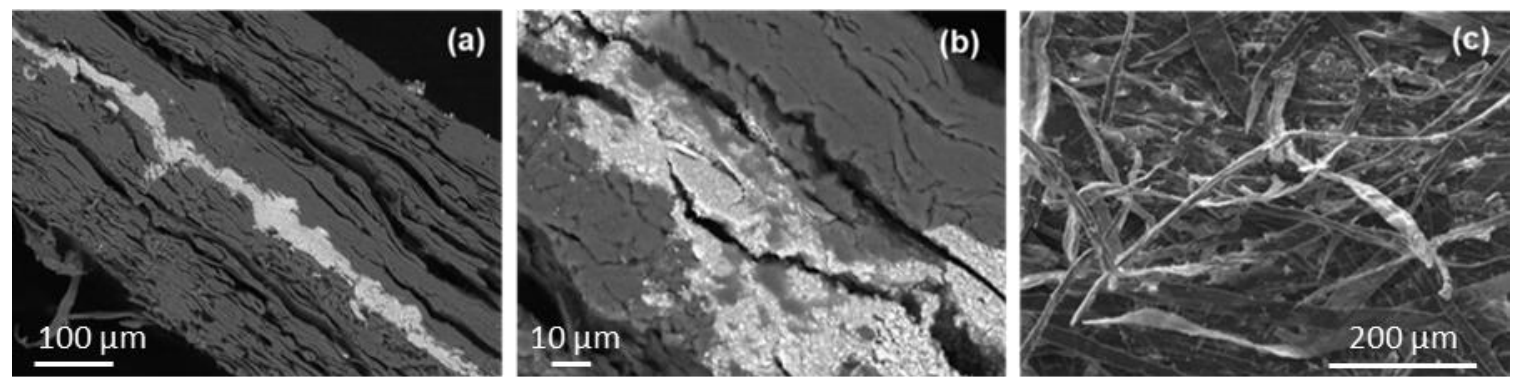

Fig. 7. SEM micrographs of the cross section of a reference-reference welded sample (BSE, welding time 1s) (a,b). SEM micrograph of a peeled uncoated surface obtained after testing a reference-uncoated sample (SE, welding time $0.5 \mathrm{~s}$ ) (c)

Figure 8 shows SEM images of a reference-uncoated welded interface obtained with a $0.5 \mathrm{~s}$-welding time. The welding joint appeared undamaged, as interfaces between coating layer and paper pulp were continuous and showed no cracks nor pores. This observation suggests that US welding succeeded in creating a good intimate contact between coated and uncoated board pieces. Thus, it is not possible to claim which side is the reference board based only on the observation of Fig. 8b. Of course, the observation of Fig. 8 a confirms that the uncoated surface is on the upper right side of the picture. It was not obvious that these two surfaces, which display very different properties, could be able to develop adhesion. It seems that the latter is promoted by the flowing and melting of binders, which create bridges between pigment agglomerates and paper fibers (Fig. 8c). Thus, polymer binders and paper fibers are compatible enough to allow the welding 
between these two surfaces. This result is confirmed by the observation of uncoated peeled surfaces (Fig. 7c). Some residual aggregates of mineral pigments and binders can be observed on the fibers ripped during the peeling.
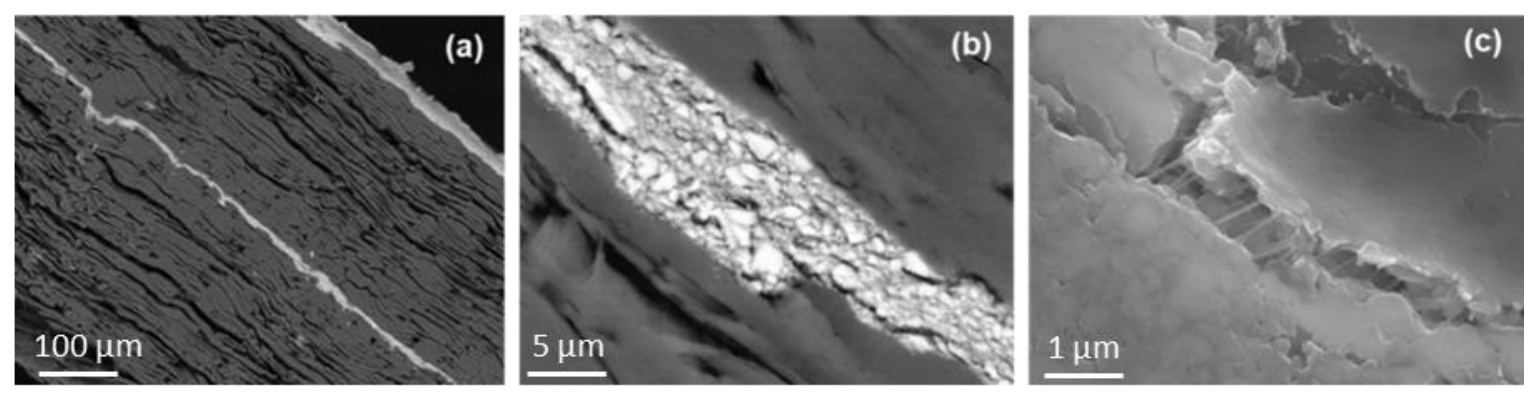

Fig. 8: SEM micrographs of the cross section of a reference-uncoated welded sample (welding time $0.5 \mathrm{~s})$ obtained in BSE $(\mathrm{a}, \mathrm{b})$ and SE (c) mode

To conclude, the same adhesion mechanisms were triggered when changing the welding time $(0.5 \mathrm{~s}$ and $1 \mathrm{~s})$. On one hand, a welding time of $1 \mathrm{~s}$ produced much more degradation, especially delamination inside the fibrous layers, but allowed the coating layer to penetrate deeper inside the fibrous network. On the other hand, $0.5 \mathrm{~s}$ welding times showed less degradation, but led to partially welded interfaces. An intermediate welding time could be a good compromise to obtain strong joints without damaging boards.

\section{Discussion}

A previous study performed on the US welding of papers showed that good adhesion was achieved when welding papers with high lignin and hemicelluloses contents (Regazzi et al. 2019). Based on the studies of the vibrational welding of wood (Gfeller et al. 2003), the development of adhesion originated to a large extent from a thermoplastic welding mechanism. Indeed, the amorphous polymers of wood in the paper pulp (lignins and hemicelluloses) exhibited creep while the welding temperature was above their glass transition temperatures to form a matrix that coated the paper fibers and filled the voids in between. To a lesser extent, chemical reactions resulting from the degradation of wood polymers at high temperature might have contributed to the establishment of adhesion.

The results presented here show that it is not possible to weld uncoated FBBs. The lignin and hemicelluloses contents of the FBB are not high enough for the material to initially present some weldability (i.e. $0 \%$ lignin and $20 \%$ hemicelluloses in the outer layers, $15 \%$ lignin and 20\% hemicelluloses in the inner layers). However, it was possible to develop adhesion by US welding with coated FBB provided that the total coating weight at the interface ( 25 to $30 \mathrm{~g} / \mathrm{m}^{2}$ ) and the binder content in the coating formulation (10 to 12 wt.\%) were high enough. Thus, weldability results from the deposition of a coating layer. SEM observations revealed a continuous interface between coating layer and paper fibers in reference-uncoated welded boards. The formation of this continuous interface resulted from the melting and flowing of the binder, herein styrene acrylate, which is a thermoplastic polymer. The melting of styrene acrylate is supposed to happen through interfacial and viscoelastic friction as it is when welding thermoplastics in general (Grewell and Benatar 2007). Melted styrene acrylate flowed near the welded zone to form a matrix, joining together the fibrous layer and the porous coating layer. This phenomenon is similar to those observed for the vibrational welding of wood (Gfeller et al. 2003) and the US welding of papers, except that styrene acrylate acts as a substitute for the flowing of wood 
polymers. This also explains why the mechanical performances of the welding boards increased with the coating weight and the binder content. Both increases led to a larger amount of binders available near the welding interface which is in favor of the formation of the thermoplastic matrix. In contrast, when the coating weight and the binder content were too low, there was not enough binder to strengthen the interfacial zone. It might appear surprising to obtain such a result with only 10 to $12 \%$ of styrene acrylate in the coating layer. Indeed, previous results on the US welding of papers have shown that a total of $20 \%$ of lignins and hemicelluloses in the paper pulp was not enough to generate adhesion (Regazzi et al. 2019). However, the binder content is often heterogenous through the thickness of the coating layer and the top surface is expected to be richer in binder (Zhen and Wang 2013). Moreover, the lower temperature observed at the welding joint when assembling coated FBBs is also consistent with previous observations. Assuming that the energy absorbed by the welded boards is identical regardless of the coating content, the observed discrepancies in peak temperature might be explained by the thermoplastic behaviour of styrene acrylate. Indeed, binders are expected to consume part of the transmitted energy to melt. For higher coating weights, the amount of binders increases, so more energy is required to melt them all. It could explain why the increase in coating weight leads to lower peak temperature.

As mentioned previously, the welded interface was partially burnt in all tested samples. Longer welding times resulted in more damaged interfaces. The temperature at the interface exceeded $300{ }^{\circ} \mathrm{C}$, which is above the degradation temperature of paper components and styrene acrylate. However, the $0.5 \mathrm{~s}$ set-up corresponds to the minimal welding conditions required to assemble coated FBBs. It was not possible to weld boards without at least slightly burnishing the tested samples. Thus, the development of adhesion might also originate from thermoset mechanisms provoked by chemical reactions of degradation occurring at high temperature between paper fibers and coating, as was observed for the vibrational welding of wood (Ganne-Chédeville et al. 2006; Delmotte et al. 2008). This suggests that the "thermoset" contribution is required to generate adhesion in coated FBBs. However, reaching high temperatures has also resulted in the degradation of the fibre network. Cohesive failures propagating inside the fibrous layers of welded boards were observed at low peeling strength $(160 \mathrm{~N} / \mathrm{m})$ in most $1 \mathrm{~s}$-welded samples. A cohesive initiation or propagation theoretically attests that adhesive bonding at the interface is stronger than the bonded material, which is generally a good sign regarding mechanical performances of the welded joint. But a cohesive propagation at less than $160 \mathrm{~N} / \mathrm{m}$ inside the FBB indicates low mechanical properties. Reaching high temperatures has probably led to degradation inside the material (fibre-to-fibre bonding, quality and strength of the fibrous network), which eased delamination inside the FBB layers when peeling. The binder content and the coating weight might also influence the level of degradation in welded boards considering their relationship with the peak temperature. The coated boards could not be welded without being burnished, which is an issue regarding packaging applications. Further studies may be required to lower the degradation of US welded boards by optimizing welding conditions or coating formulations.

\section{CONCLUSIONS}

1. Significant adhesion levels were obtained when assembling by US welding coated folding boxboards. Adhesion is enabled by the presence of binders in the coating. The 
performances of the welded boards fit the requirements of most packaging applications.

2. The weldability of coated boards increases with the coating weight and the binder content in the coating formulation. These parameters can be adjusted to adapt the mechanical performances of welded joints. A total coating weight of 20 to $25 \mathrm{~g} / \mathrm{m}^{2}$ at the welding interface and a binder content of 10 to $12 \mathrm{wt} \%$ in the coating formulation are required to develop adhesion under US compression.

3. The establishment of adhesion in coating layers is mainly attributed to a thermoplastic mechanism (melting and flowing of the binders forming a continuous matrix at the welding interface) and supposedly to chemical bonding created by degradation reactions.

4. It is necessary to rise above the degradation temperature of boards and coated layers to be able to weld. Thus, the welded interface is partially burnt. It may be an issue for the development of the technology regarding the aesthetic of the joint and potential health and safety concerns related to degradation products.

5. There is room for improvement by optimizing welding parameters or coating formulations. Assembling folding board boxes using an adhesive-free process is possible and has good environmental and economic prospects.

\section{ACKNOWLEDGMENTS}

The authors acknowledge the financial support from Institut Carnot PolyNat (ANR16-CARN-0025-01) and Agence Nationale de la Recherche (ANR-17-CE08-0055).

\section{REFERENCES CITED}

Abboud, L. (2019). "Unilever vows to reduce use of plastic packaging," (https://www.ft.com/content/e003c2ac-e82e-11e9-a240-3b065ef5fc55), Accessed March 16, 2021.

Andersson, C. (2008). "New ways to enhance the functionality of paperboard by surface treatment-A review," Packaging Technology and Science 21(6), 339-373. DOI: $10.1002 /$ pts.823

ASTM D 3167 - 10 (2017). "Standard test method for floating roller peel resistance of adhesives," ASTM International, West Conshohocken, USA.

Confederation of European Paper Industries (CEPI) (2018). Key Statistics 2018. European Pulp \& Paper Industry, (https://www.cepi.org/wpcontent/uploads/2020/10/Final-Key-Statistics-2018.pdf), Brussels, Belgium.

Delmotte, L., Ganne-Chédeville, C., Leban, J. M., Pizzi, A., and Pichelin, F. (2008). “CPMAS 13C NMR and FT-IR investigation of the degradation reactions of polymer constituents in wood welding," Polymer Degradation and Stability 93(2), 406-412. DOI: 10.1016/j.polymdegradstab.2007.11.020

Ganne-Chédeville, C., Properzi, M., Pizzi, A., Leban, J. M., and Pichelin, F. (2006). "Parameters of wood welding: A study with infrared thermography," Holzforschung 60(4), 434-438. DOI: 10.1515/HF.2006.06 
Gfeller, B., Zanetti, M., Properzi, M., Pizzi, A., Pichelin, F., Lehmann, M., and Delmotte, L. (2003). "Wood bonding by vibrational welding," Journal of Adhesion Science and Technology 17(11), 1573-1589. DOI: 10.1163/156856103769207419

Grewell, D., and Benatar, A. (2007). "Welding of plastics: Fundamentals and new developments," International Polymer Processing 22(1), 43-60. DOI: $10.3139 / 217.0051$

Levy, A., Le Corre, S., and Villegas, I. F. (2014). "Modeling of the heating phenomena in ultrasonic welding of thermoplastic composites with flat energy directors," Journal of Materials Processing Technology 214(7), 1361-1371. DOI:

10.1016/j.jmatprotec.2014.02.009

Li, H., Qi, Y., Zhao, Y., Chi, J., and Cheng, S. (2019). "Starch and its derivatives for paper coatings: A review," Progress in Organic Coatings 135, 213-227. DOI: 10.1016/j.porgcoat.2019.05.015

Regazzi, A., Viguié, J., Harthong, B., Dumont, P. J., Imbault, D., Peyroux, R., Rueff, M., Charlier, Q., Guérin, D., Leroy, L., Krouit, M., and Petit-Conil, M. (2019). "Ultrasonic welding of 100\% lignocellulosic papers," Journal of Materials Science 54(19), 12938-12950. DOI: 10.1007/s10853-019-03763-7

Villegas, I. F. (2015). "In situ monitoring of ultrasonic welding of thermoplastic composites through power and displacement data," Journal of Thermoplastic Composite Materials 28(1), 66-85. DOI: doi.org/10.1177/0892705712475015

Zhen, Z. H., and Wang, Z. S. (2013). "Coating binder migration and affected parameters: Influence of coating process," Advanced Materials Research 791, 187-191. DOI: 10.4028/www.scientific.net/AMR.791-793.187

Article submitted: March 15, 2021; Peer review completed: May 9, 2021; Revised version received and accepted: June 23, 2021; Published: July 1, 2021.

DOI: 10.15376/biores.16.3.5766-5779 